\title{
The parathyroid leptin axis
}

\author{
Jaya George $\mathbb{1}^{1}$
}

Received: 28 February 2017 / Accepted: 17 April 2017 / Published online: 28 April 2017

(C) Springer Science+Business Media New York 2017

Obesity has reached record proportions in the last several decades and with that a host of co-morbidities most notably increased type II diabetes mellitus, hypertension and cardiovascular disease. It has also led to the concept of a bonefat axis. Historically obesity was associated with increased bone health while more recent evidence suggests an increased fracture risk among obese individuals.

Mediators of this interaction include adipokines such as leptin. Adipose tissue is no longer just considered a fat store but an important source of inflammatory cytokines, as well as adipokines which act peripherally as well as centrally. It was the discovery of leptin, produced mainly by adipose tissue that first led to the recognition of adipose tissue as an endocrine organ [1]. Serum leptin levels have been strongly positively correlated with fat mass in several studies [1,2]. Leptin exerts its effects following binding to specific leptin receptors located in the central nervous system to suppress food intake and increase energy expenditure. Other than its role on body mass, leptin also modulates the hypothalamicpituitary axis, gonadal function, and the adrenals [3]. While the most important determinant of circulating leptin concentrations is body-fat mass, it is stimulated by insulin, glucocorticoids, and overfeeding and is suppressed by fasting, cAMP, and $\beta 3$-adrenoreceptor agonists [2].

Leptin is produced by bone marrow adipocytes, as well as by extramedullary fat. Marrow adipose tissue derived leptin directly influences osteoblastogenesis while extramedullary leptin acts on the hypothalamus and B adrenergic

Jaya George

jaya.george@wits.ac.za

1 National Health Laboratory Services and University of Witwatersrand, Parktown, South Africa receptors. Studies suggest that leptin is also involved in the regulation of calcium regulating hormones, including parathyroid hormone $(\mathrm{PTH}), 1,25(\mathrm{OH}) 2$ vitamin $\mathrm{D} 3(1,25$ (OH)D3), and fibroblast growth factor 23 (FGF-23) [4]. Both leptin and PTH exhibit a diurnal rhythm with nearly identical mid-morning nadirs and mid-night peaks that are independent of an endogenous circadian clock [5].

The primary role of PTH, produced by the parathyroid glands, is to prevent or reverse acute hypocalcemia, which it does by mobilizing calcium from bones, stimulating renal calcium reabsorption, and increasing the production of $1,25(\mathrm{OH}) \mathrm{D} 3$ which increases intestinal calcium absorption.

An inter-relationship between leptin and PTH was first suggested because patients with primary hyperparathyroidism have significantly higher leptin levels than healthy controls. However this is not true across all studies $[6,7]$. The reasons for the increased PTH seen in obesity are not known but have been attributed amongst others reasons to decreased $1,25(\mathrm{OH}) \mathrm{D}_{3}$ from FGF-23 secretion [8]. Further evidence for their interaction is suggested by the fact that both leptin and PTH have been linked with complications arising from obesity such as hypertension and heart disease and higher PTH concentrations have been shown to be predictive of increase cardiovascular mortality [9]. Data from our center suggests that PTH is positively associated with the metabolic syndrome because of its association with blood pressure and waist circumference and independent of serum 25(OH)D levels [10].

Like leptin, PTH shows a direct relationship with obesity [7]. It is much higher in those who are morbidly obese and concentrations have been shown to drop after bariatric surgery. Furthermore, both osteocytes and adipocytes arise from common precursor mesenchymal stem cells. Local administration of leptin to the hypothalamus leads to an 
indirect suppression of osteoblasts while systemic administration causes PTH-like estrogenic-like bone formation.

Hoang et al. noted that in patients with primary hyperparathyroidism, either due to adenoma or hyperplasia, serum leptin levels dropped after surgical removal of the parathyroid with specific single nucleotide polymorphisms of the leptin receptor associated with parathyroid gland size [11]. Further work by Hoang's group has demonstrated the presence of leptin and leptin receptor mRNA in chief cells from patients with hyperparathyroidism due to adenoma and hyperplasia, as well as in normal parathyroid gland [7]. They also showed that parathyroid PTH secretion increased in parathyroid explants on exposure to leptin and that decreased with leptin receptor inhibition [12].

It is possible that leptin effects on PTH are mediated not just via the leptin receptor. In this issue by Lopez et al. sheds some light on the leptin /PTH interaction [13]. Using wild type (WT) mice and leptin receptor deficient mice they have shown a direct effect of leptin on PTH secretion. Leptin is known to stimulate secretion of FGF-2 and inhibit $1,25(\mathrm{OH}) \mathrm{D}_{3}$ secretion, which can reduce PTH concentrations. However Lopez et al. showed that administration of leptin to WT mice increased PTH secretion with no change in ionized calcium, phosphate, FGF-23 or $1,25(\mathrm{OH}) \mathrm{D}_{3}$. Immunohistochemical staining showed the presence of leptin receptors in chief cells of parathyroid glands in mice. This provides evidence for a fat /PTH axis. However there are no similar studies showing the existence of PTH receptors on adipose tissue; although PTH has been shown to increase cytosolic calcium of adipocytes and this is receptor mediate.

The papers add to the body of evidence for complex interactions between fat and bone through mediators such as PTH and leptin and raise more questions as how these hormones regulate each other. The understanding of the whole array of molecules involved in this system and the attendant signaling pathways will continue to be an area for research.

\section{Compliance with ethical standards}

Conflict of interest The authors declare that they have no competing interests.

Ethical approval This article does not contain any studies with human participants or animals performed by any of the authors.

\section{References}

1. S. Margetic, C. Gazzola, G.G. Pegg, R.A. Hill, Leptin: a review of its peripheral actions and interactions. Int. J. Obes. Relat. Metab. Disord. 26, 1407-1433 (2002). doi:10.1038/sj.ijo.0802142
2. H.K. Park, R.S. Ahima, Physiology of leptin: energy homeostasis, neuroendocrine function and metabolism. Metabolism 64, 24-34 (2015). doi:10.1016/j.metabol.2014.08.004

3. D. Garcia-Galiano, J. Allen Susan, F. Elias Carol, Role of the adipocyte-derived hormone leptin in reproductive control. Horm. Mol. Biol. Clin. Investig. 19, 141-149 (2014). doi:10.1515/ hmbci-2014-0017

4. K. Tsuji, T. Maeda, T. Kawane, A. Matsunuma, N. Horiuchi, Leptin stimulates fibroblast growth factor 23 expression in bone and suppresses renal 1 1 ,25-dihydroxyvitamin D3 synthesis in leptin-deficient ob/ob mice. J. Bone Miner. Res 25, 1711-1723 (2010). doi:10.1002/jbmr.65

5. G.E.-H. Fuleihan, E.B. Klerman, E.N. Brown, Y. Choe, E.M. Brown, C.A. Czeisler, The parathyroid hormone circadian rhythm is truly endogenous-A general clinical Research center study*. J. Clin. Endocrinol. Metab. 82, 281-286 (1997). doi:10.1210/jcem. 82.1.3683

6. D.A. de Luis, G.D. Soto, R. Conde, O. Izaola, B. de la Fuente, Relation of leptin and adiponectin with cardiovascular risk factors, intact parathormone, and vitamin D levels in patients with primary hyperparathyroidism. J. Clin. Lab. Anal. 26, 398-402 (2012). doi: $10.1002 /$ jcla. 21541

7. E. Kamycheva, J. Sundsfjord, R. Jorde, Serum parathyroid hormone level is associated with body mass index. The 5th Tromso study. Eur. J. Endocrinol. 151, 167-172 (2004). doi:10.1530/eje.0. 1510167

8. E. Ishimura, S. Okuno, N. Tsuboniwa, K. Norimine, S. Fukumoto, K. Yamakawa, T. Yamakawa, S. Shoji, Y. Nishizawa, M. Inaba, Significant positive association between parathyroid hormone and fat mass and lean mass in chronic hemodialysis patients. J. Clin. Endocrinol. Metab. 98, 1264-1270 (2013). doi:10.1210/jc. 2012-3883

9. E. Hagstrom, P. Hellman, T.E. Larsson, E. Ingelsson, L. Berglund, J. Sundstrom, H. Melhus, C. Held, L. Lind, K. Michaelsson, J. Arnlov, Plasma parathyroid hormone and the risk of cardiovascular mortality in the community. Circulation 119, 2765-2771 (2009). doi:10.1161/CIRCULATIONAHA.108. 808733

10. J.A. George, S.A. Norris, M. Toman, T. Snyman, N.J. Crowther, Visceral adiposity is a predictor of parathyroid hormone levels in healthy adults. J. Endocrinol. Invest. 39, 447-453 (2016). doi:10. 1007/s40618-015-0400-x

11. D. Hoang, N. Broer, S.A. Roman, X. Yao, N. Abitbol, F. Li, J.A. Sosa, G.R. Sue, A.T. DeWan, M.L. Wong, J. Licinio, C. Simpson, A.Y. Li, N. Pizzoferrato, D. Narayan, Leptin signaling and hyperparathyroidism: clinical and genetic associations. J. Am. Coll. Surg. 218, 1239-1250 (2014). doi:10.1016/j.jamcollsurg. 2013.11.013. e1234

12. D. Hoang, N. Broer, J.A. Sosa, N. Abitbol, X. Yao, F. Li, F. Rivera-Molina, D.K. Toomre, S.A. Roman, G. Sue, S. Kim, A.Y. Li, G.G. Callender, C. Simpson, D. Narayan, Leptin is produced by parathyroid glands and stimulates parathyroid hormone secretion. Ann. Surg. (2016). doi:10.1097/sla.00000000 00002004

13. I. Lopez, C. Pineda, R. AI., M.E. Rodriguez-Oritz, J.M. DiazTocados, R. Rios, J.M. Rodrigiez, E. Aguilera-Tejero, Y. Almaden, Leptin directly stimulates parathyroid hormone secretion. Endocrine (2017). doi:10.1007/s12020-016-1207-z 